\title{
Effect of exposure to carbofuran on the behavior and metabolism of the Atlantic Forest lambari Deuterodon iguape (Eigenmann 1907), a native species from Brazil
}

Ricardo Claudionor Mendes

Instituto de Pesca

MARCELO Barbosa HENRIQUES ( $\boldsymbol{\sim}$ henriquesmb@gmail.com )

Governo do Estado de São Paulo https://orcid.org/0000-0003-1419-9121

Edison Barbieri

Instituto de Pesca

\section{Research Article}

Keywords: Ammonia excretion, biomarkers, Carbamate, Metabolic rate, Pollutants

Posted Date: February 18th, 2021

DOl: https://doi.org/10.21203/rs.3.rs-186704/v1

License: (c) (i) This work is licensed under a Creative Commons Attribution 4.0 International License.

Read Full License 


\section{Abstract}

One of the major causes of aquatic biodiversity loss is the contamination of the environment by pesticides. Although there is a considerable amount of studies on the subject, there are still few that deal with the effects of carbofuran on native species in Brazil. Although carbofuran is widely used in Brazil, its action on native organisms, such as the Atlantic Forest lambari Deuterodon iguape, has not yet been studied. This work aimed to evaluate the effects of exposure to carbofuran on the fish D. iguape, considering the behavior and specific oxygen consumption and specific ammonia excretion as end points. Opercular movements, dorsal fin movements and swimming speed were analyzed as behavioral parameters. To assess specific oxygen consumption and specific ammonia excretion, fish were subjected to concentrations of $0.0,0.05,0.1,0.25$, and $0.5 \mathrm{mg} / \mathrm{L}$, for 24 hours. For behavior analysis, fish remained exposed to carbofuran at concentrations: $0.0,0.01,0.05,0.1$ and $0.5 \mathrm{mg} / \mathrm{L}$, in periods of $0,2,24$ and 48 hours. The behavior was studied through filming, analyzed with the free software, Tracker 4.92 (Open Source Physics). The results showed that there was a decrease in opercular movements $(-8 \% \pm 2.65)$, in dorsal fin movements $(-18.6 \% \pm 2.97)$, as well as in swimming speed $(-66.4 \% \pm 1.83)$. There was an increase in oxygen consumption of $58.4 \%$ and ammonia excretion by $90.6 \%$ in fish exposed to the highest concentration of carbofuran. Thus, it is concluded that carbofuran altered D. iguape 's behavior, oxygen consumption and ammonia excretion. The species was sensitive to carbofuran concentrations and can be used as a bioindicator.

\section{Introduction}

The increase in human activities involving pesticides contributes to the increase in the concentrations of these pollutants in water bodies, threatening both aquatic and terrestrial biota as well as human health (Reigala et al. 2014). Despite the fact that pesticides guarantee an increase in agricultural productivity, by protecting crops from their "natural enemies", their inadequate management can compromise soils, water sources and, consequently, non-target organisms (Gunningham and Sinclair 2005; Campos-Garcia et al. 2016). In this sense, the constant use of these substances causes great concern, because once present in the environment, they affect all the biota that is exposed to them in different ways (Barbieri et al. 2013; Santiago-Moreira 2013; Ruíz-Hidalgo et al. 2016).

Toxic compounds such as pesticides can affect aquatic organisms by compromising their behavioral, nutritional, and physiological status (Van der Oost et al. 2003; Lal 2007). For this reason, studies of the behavior and metabolism of fish and shrimp can assist in monitoring the environmental quality where these organisms are present. Using behavior and metabolism as a biomarker, it is possible to analyze the general physical state of these animals when in contact with certain toxic substances (Barbieri 2007b).

Among pesticides, carbamates are one of the most used in Brazil because they are efficient over a large number of insects (Barbieri et al. 2013). Carbofuran, the largest representative of the carbamate class, produces deleterious effects capable of reaching non-target organisms as fish (Herbrandson et al. 2003). The scarcity of knowledge about the risks that pesticides can cause on native fish is worrying, since their 
demand and use in the environment has increased in recent years, raising concerns about the toxicity of these substances in the behavioral and physiological processes of aquatic organisms (Britto et al. 2012; Campos-Garcia et al. 2016; Barbieri et al. 2018). Due to the great potential reach that pesticides have in aquatic environments, it is necessary to determine what levels of exposure are impacting the species present in these environments (Klaper et al. 2010). Although carbofuran is widely used in Brazil, its action on native organisms, such as the Atlantic Forest lambari Deuterodon iguape, has not yet been studied. Marques et al. (2007) revealed that of 152 water samples analyzed, only $24 \%$ showed the presence of pesticides, particularly carbofuran $(0.01$ and $0.5 \mathrm{mg} / \mathrm{L})$ in the São Paulo region.

Jash and Bhattacharaya (1983) observed in fish that the effects caused by exposure to carbofuran caused the inhibition of acetyl cholinesterase, affecting nervous and muscular impulses. Little and Finger (1990) studied post-exposure to different concentrations of pesticides, noting changes in behavior, as evidenced by decreased swimming activity. Many of these functions are visibly altered by pollutants, which cause fish to show altered signs in vital activities, since their senses are affected (Barbieri 2007a). Some behaviors, which are affected in some way, include latency in eating, aggressiveness, adverse response to a predator, variation in breathing, altered swimming ability and capacity, and consequent effects on reproduction (Baldwin et al. 2009).

The behavioral responses of fish can be used as important biomarkers (Bosisio et al. 2017), especially swimming and breathing (Rand 1984; Barbieri, 2007b; Ferarini et al., 2016), which are parameters that can be easily assessed when fish are exposed to toxic substances (Little and Finger 1990; Christiansen et al. 1998; Maxuwell and Dutta 2005).

The test organisms who can be cultivated in the laboratory and are the most used, internationally, in ecotoxicological tests are microalgae (Pseudokirchneriella subcaptata), cladocerans (Daphnia similis or Ceriodaphnia dubia) and fish (Danio rerio and Pimephales promelas) (Lombardi 2004). Testing the hypothesis of viability in other organisms, which present the basic principles for use in the toxicity tests suggested by Zagatto and Bertoletti (2006), fish of the species Deuterodon iguape, belonging to the Characidae family, found in watersheds in neotropical and subtropical regions of Brazil, were used in this study. Characidae is the largest of the families in the Characiform order, and contains $65 \%$ of the species of that order, distributed into 12 subfamilies, 167 genera and 980 species, totaling $21 \%$ of the entire neotropical ichthyofauna (Fonseca et al. 2017). The Deuterodon iguape lambari is an endemic species of small rivers and streams in the region of tropical and subtropical forests and has wide market possibilities (Henriques et al. 2019). Recent studies have identified that, in addition to selling them for human consumption, they can be used as live bait for sport fishing (Henriques et al. 2018).

The objective of this study was to evaluate the effects of exposure to carbofuran on lambaris (Deuterodon iguape), using the behavioral parameters of opercular movement, dorsal fin movement, swimming speed, as well as the metabolic parameters of specific oxygen consumption and specific ammonia excretion. 


\section{Materials And Methods}

\section{Pollutant used}

The chemical substance used was a carbamate (2,3-dihydro-2,2-dimethyl-7-benzofuranyl methyl carbamate) $(99.5 \%$, Sigma), a chemical pesticide popularly known as carbofuran.

\section{Experimental design}

Specimens of Deuterodon iguape were obtained from the Instituto de Pesca (Fisheries Institute). After the 7-day acclimatization period, 50 fish were used. Twenty five individuals, with an average weight of 11.76 $\mathrm{g}( \pm 1.90 \mathrm{~g})$ and an average length of $11.02 \mathrm{~cm}( \pm 1.41 \mathrm{~cm})$, were used for the analysis of behavior parameters and the other 25 individuals, with an average weight of $10.35 \mathrm{~g}( \pm 3.82 \mathrm{~g})$ and an average length of $10.75 \mathrm{~cm}( \pm 1.24 \mathrm{~cm})$, were used for the analysis of routine metabolism. No fish was used more than once in each experiment. For both experiments, the animals were divided into 5 experimental groups $(n=5)$, each group was in a $30 \mathrm{~L}$ glass aquarium, with constantly aerated water, a pH of 6.5 , and controlled temperature between 20 and $21^{\circ} \mathrm{C}$. For the behavior groups, there was an extra aquarium (Filming Record Aquarium-ARF) with the same dimensions and characteristics (without carbofuran), in which the filming and collection of the behavior data were made. This method aimed to test the poststress behavior of aquarium transfer. The intention was to simulate escape stress or even hunting for food.

Water chemical analysis to confirm exposure concentrations of carbofuran was performed using an HPLC system (1200 series, Agilent Technologies, CA, USA) coupled to a 6130 quadrupole mass spectrometer with a G1978B multimode ion source [electrospray ionization (ESI) and atmospheric pressure chemical ionization (APCl)]

This study followed the ethical principles for animal experimentation adopted by the Brazilian School of Animal Experimentation (COBEA) and received authorization (no.14/2018) from the Ethics Committee on Animal Experimentation of the Fisheries Institute, São Paulo, Brazil.

The carbofuran concentrations used for the behavior parameters were $0.0 ; 0.01 ; 0.05 ; 0.1$ and $0.5 \mathrm{mg} / \mathrm{L}$, and data collections were performed during the periods of $0 \mathrm{~h}, 2 \mathrm{~h}, 24 \mathrm{~h}$, and $48 \mathrm{~h}$. In each group-to-group period, they were transferred to the ARF for filming, which began after one minute of the fish's stay. Each group of the fish were subjected a different concentration. To obtain the carbofuran desired concentration, the necessary volume of the main (mother) substance $(1 \mathrm{mg} /$ carbofuran $/ \mathrm{mL})$ was calculated to each volume of glass aquarium. The behavior was analyzed in an aquarium for each fish. The filming was done in two shots (profile and aerial) simultaneously, and lasted 1 minute, to record the opercular movements, dorsal fins, and swimming speed. The Video resolution: FHD $1920 \times 1080,30$ frames per second. In order to check the swimming speed, the footage was submitted to the Tracker 4.92 software (Open Source Physics), which through sequences of the images produced several frames, 
allowing the addition of coordinate axes. The program creates mass points, with different colors, indicating the path of each fish, avoiding the exchange of fish. Each fish was assessed individually. Then, using the mass point, which is the location of each fish on the axes, it was possible to verify the trajectory of each individual over the 60 seconds of filming. At the end of the trajectory, the program reported the swimming speed and the individual's position in the $X$ and $Y$ coordinates. The number of opercular movements and dorsal fins were counted in a direct, visual way through the Filming Reports (Henriques et al. 2018). For each treatment, including controls, the fish were fasted for 24 hours and then were kept for 2 hours in an aquarium with $30 \mathrm{~L}$ of water.

For the analysis of metabolism, the remaining 25 fish were used, which were exposed to concentrations of $0.0,0.05,0.1,0.25,0.5 \mathrm{mg} / \mathrm{L}$ of carbofuran, for a period of 24 hours. After this period of exposure to the contaminant, the specimens were distributed in cylindrical glass respirometers, with one fish per respirometer. The respirometers were kept in a closed system with continuous water circulation, to mitigate the stress caused by handling, the specimens were kept inside the respirometers for one hour with continuous water circulation. Soon after, the respirometers were closed, interrupting the internal water circulation, and isolating them from the closed system with continuous circulation, for one hour. Immediately after one hour, water was collected from respirometers to analyze oxygen consumption and ammonia excretion (Barbieri and Doi 2011).

For each treatment, including controls, the fish were fasted for 24 hours and then were kept for 2 hours in an aquarium with $30 \mathrm{~L}$ of water. Different amounts of carbofuran were added to each aquarium with precision pipettes to ensure a homogeneous distribution in the aquarium and to obtain the final concentration determined, just before the introduction of the fish.

Specific oxygen consumption was determined by the difference in dissolved oxygen concentrations between the beginning and the end of an hour, according to the volume of the respirometer, the wet weight of the fish, and the confinement time $\left(\mathrm{mLO}_{2} / \mathrm{g} / \mathrm{L} / \mathrm{h}\right)$. Dissolved oxygen was determined according to the method of Winkler (1888).

The collections of water for the analysis of the specific ammonia excretion were carried out simultaneously with the collections for analysis of specific oxygen consumption. Ammonia excretion was determined by the difference between ammoniacal nitrogen concentrations at the beginning and at the end of an hour, according to the volume of the respirometer, the wet weight of the fish, and the confinement time $(\mathrm{mg} / \mathrm{g} / \mathrm{L} / \mathrm{h})$. Ammoniacal nitrogen was determined by the Nessler (1856) method (APHA, 1995).

\section{Statistical analysis}

The behavioral data were evaluated, after checking the normal distributions (Kruskal-Wallis test) and homoscedasticity (Levene test), according to the means and standard deviations obtained by the statistical analysis of ANOVA (one-way). 
The means and standard deviation of the routine metabolism data were submitted to the Shapiro-Wilk normality test and Levene's homoscedasticity test. Subsequently, the ANOVA test was applied. Before statistical tests, all data tested using Tukey test $(p<0.05)$

\section{Results}

\section{Behavior: opercular movements}

In the 0-hour exposure period, the average of opercular movements in the concentrations used, did not present statistical difference in relation to the control (Fig. 1). In the 24- and 48-hours periods, the fish demonstrated a drop in the opercular rhythm in the concentrations used when compared to the control, with statistical differences observed with the concentrations of $0.01 \mathrm{mg} / \mathrm{L}$ to $0.5 \mathrm{mg} / \mathrm{L}$ (Fig. 1).

\section{Behavior: dorsal fin movements}

During the 0-hour exposure period, the means of opercular movements showed statistical difference in relation to the control only in the concentration of $0.5 \mathrm{mg} / \mathrm{L}$. Fish exposed in the periods of 2, 24 and 48 hours, showed statistical differences in relation to the control in all concentrations used (Fig. 2).

\section{Behavior: swimming speed}

Except for the 0-hour exposure period, the averages of the swimming speed of the fish were statistically different in relation to the control in all concentrations and exposure periods used (Fig. 3).

\section{Metabolism: Specific oxygen consumption}

The averages of specific oxygen consumption of individuals exposed to carbofuran increased as the concentration increased (Fig. 4). There was a statistical difference in relation to the control in concentrations of $0.1,0.25$, and $0.5 \mathrm{mg} / \mathrm{L}$.

\section{Metabolism: Specific ammonia excretion}

The results for specific ammonia excretion indicated an increase in excretion as the carbofuran concentration increased; however, there was a statistical difference only in the concentration of $0.5 \mathrm{mg} / \mathrm{L}$ (Fig. 5).

\section{Discussion}

Rand (1984) cataloged a series of fish behaviors that are used as indicators of toxicity. Among these, swimming is considered a good indicator of changes due to water pollution, including substances 
present at sublethal levels. Swimming time until tiredness and oxygen consumption during exercise are adequate to study acute effects of toxins on the environment, since they provide quick and easily measurable responses in different species of fish (Little and Finger 1990). Studies comparing the duration of swimming activity, feeding, and predator escape in the rainbow trout, Oncorhynchus mykiss, demonstrated that these parameters were reduced by sublethal exposure to chemicals (Little et al. 1990). Moreover, in studies with Mugil platanus, there was a change in swimming capacity when exposed to different surfactants (Barbieri et al. 1998; Barbieri 2007b).

The changes in the behavior parameters evaluated in this work showed similarities with the studies by Rand and Petrocelli (1985), who tested behavioral parameters of swimming as a biomarker in their experiment, and found a decrease in the speed of swimming in individuals exposed to pesticides. Nile tilapia (Oreochromis niloticus) exposed to carbofurano detergent also had its swimming capacity decreased as the xenobiotic concentration increased (Campos-Garcia et al., 2015).

In the present study it was possible to observe changes in the behavior of $D$. iguape, exposed to carbofuran similar to those reported in the works of Pereira et al. (2012) and Diniz and Honorato (2012), when fish were exposed to pesticides and showed changes in their behavior. According to Campos-Garcia et al. (2016), the degree of toxicity to fish varies due to the quantity and availability of the pollutant in the environment, plus the exposure time of the organism. Thus, for $D$. iguape, greater effects of carbofuran were also observed, altering its behavior during longer periods of exposure. According to Iwama et al. (2004) and Barreto and Volpato (2006), the changes suffered by fish in the respiratory parameters are the most noticeable, considering that they affect the opercular movements. These results were verified, in the present study, during the periods of 2, 24 and 48 hours of exposure to the pollutant, corroborating with those mentioned by these authors.

Changes in swimming speed are reflected in various activities of the organism such as migration, predation, or success in the flight from predators, with serious ecological consequences (Reidy et al. 1995). In addition, the decrease in swimming speed makes it difficult to find the prey due to the reduced search area (Barbieri 2007a). This fact damages eating efficiency with the concomitant decrease in the amount of energy available for growth (Little and Finger 1990).

The studies by Little and Finger (1990), Barbieri (2007a,b) and Campos-Garcia et al. (2016) highlight the behavior of swimming as an important parameter to be used in ecotoxicology, which is confirmed in the present study, given that the loss of swimming speed of the fish, reached $56.6 \%( \pm 1.41)$ in the highest concentration of carbofuran $(0.5 \mathrm{mg} / \mathrm{L})$ during the final period of 48 hours.

Silva et al. (2006) observed that the result of the presence of pollutants initially provoked, in the studied organisms, an increase in the swimming speed and later a decrease. This result is similar to what was observed for the Atlantic Forest lambari $D$. iguape, which after an initial increase in swimming speed, there was a sequential decrease of around $50 \%$, compared to the control. The concentrations of carbofuran used in the present study resulted in a noticeable reduction in swimming speed as well as, consequently, in the other behavior parameters. Hernandez-Moreno et al. (2011) reached similar results 
when they found that the swimming capacity, related to the opercular and flipper movements, decreased when the pesticide concentration was increased.

Swimming speed is a valid parameter and a consistent index of sublethal toxicity, which can be easily incorporated into testing protocols to increase the sensitivity of the toxicity test pattern. Measurements from swimming time to tiredness can be closely monitored in the laboratory with simple equipment that can be easily adapted for use in field toxicity tests.

According to Sabra and Mehana (2015) and Santana and Cavalcante (2016), the results of studies developed with pesticides in fish always show changes in branchial functions influencing alterations in gas exchange capacity, directly affecting breathing, as well as opercular movement disorders and other related functions, which were also observed in the present study.

Several studies have shown an increase in oxygen consumption in organisms exposed to various toxins. Lemaire et al. (1996), studying the effects of aromatic compounds, found a pronounced increase in oxygen consumption in fish as the concentration of aromatics increased. On the other hand, MacLead and Smith (1966), testing the effect of wood fibers on oxygen consumption and activity of Pimephales promelas, found that with each doubling of the concentration, there was a decrease of $1 \mathrm{mg} / \mathrm{kg} / \mathrm{min}$ in consumption amid low levels of dissolved oxygen, and $0.2 \mathrm{mg} / \mathrm{kg} / \mathrm{min}$ in high levels of it. The authors also reported a significant decrease in swimming capacity, using this parameter as an indicator of stress.

In our experiments, we found a significant increase in routine metabolism as the carbofuran concentration increased. Probably, in the concentrations used during the short experimental period, the pesticide effect was not enough to alter the respiratory organs to the point of compromising their absorption of the gas. In addition, it can also be assumed that as gills are involved in osmoregulation and other metabolic processes as well as gas exchange, carbamates, even in low concentrations, impair the proper functioning of these processes, causing individuals exposed to them to spend more energy attempting to maintain homeostasis (Barbieri et al. 2018).

The changes in the specific oxygen consumption presented in this study were greater with high concentrations of carbofuran, because the higher the concentration, the greater the effect. According to Bosisio et al. (2017), changes in specific oxygen consumption are related to metabolic disorders in general, causing behavioral changes in fish. There was an increase in the specific oxygen consumption of D. iguape exposed to carbofuran, in the same way as was verified by Vargas et al. $(1991 \mathrm{a}, \mathrm{b})$ and Campos-Garcia et al. (2016) in fish exposed to plant extracts and carbofuran, respectively. In view of these changes, it was found that substances with the potential for environmental changes can cause changes in oxygen consumption in aerobic aquatic organisms.

Studies by Campos-Garcia et al. (2016) with tilapia exposed to parathion and carbofuran, observed an increase in oxygen consumption, at the different concentrations used. These results are similar to those observed in the present study, in which there was an increase in oxygen consumption, with an increase in the concentration of carbofuran. 
Barbieri et al. $(2017 a, 2018)$ indicated a significant increase in ammonia excretion with large concentrations of carbofuran, which is similar to results observed for $D$. iguape where the excretion of ammonia was greater at the highest concentration employed. De-Boeck et al. (1995) explains that protein catabolism, for the production of energy in fish, ends up generating ammonia as a final product, which indicates a constant increase in excretion. Therefore, higher concentrations of carbofuran likely increase the demand of for energy production in $D$. iguape, as measured by ammonia excretion, implying a stressful condition.

Similarly, Dhamagaye et al. (2015) found a significant increase in the amount of ammonia excretion in a study with Pangasius hypophthalmus exposed to cypermethrin. This was similar to what was observed in the present study when there was a considerable increase in ammonia excretion in the tested individuals. A study with freshwater shrimp, Macrobrachium olfersii, exposed to carbofuran, found that ammonia excretion increased when concentrations were the highest (Barbieri et al. 2013). In addition, in a study by Campos-Garcia et al. (2016) with Oreochromis niloticus exposed to carbofuran, the authors found an increase of more than $200 \%$ in ammonia excretion when fish were exposed to carbofuran. This was also similar to what occurred in $D$. iguape as the increase in ammonia excretion reached $172.8 \%$ (at $0.5 \mathrm{mg} / \mathrm{L})$.

\section{Conclusions}

It is concluded that the concentrations of carbofuran used were able to result in changes in the behavior of the fish, which were clear in the three parameters, opercular movements, dorsal fin movements and swimming speed.

The Atlantic forest lambari, D. iguape, proved to be sensitive to carbofuran and can be used as a bioindicator of water pollution in ecotoxicological studies. This study demonstrated that the concentrations used have sufficient potential to alter the behavior of the fish. Moreover, it showed that the response of these individuals to the pollutant, in addition to being useful, is an environmental concern, especially in areas where the use of carbofuran is more intense.

\section{Declarations}

- Ethics approval and consent to participate

This study followed the ethical principles for animal experimentation adopted by the Brazilian School of Animal Experimentation (COBEA) and received authorization (no.14/2018) from the Ethics Committee on Animal Experimentation of the Fisheries Institute, São Paulo, Brazil.

\section{- Consent for publication}

Not applicable" in this section. 
- Availability of data and materials

The datasets used and/or analysed during the current study are available from the corresponding author on reasonable request.

- Competing interests

The authors declare that they have no competing interests in this section.

\section{- Funding}

This study was financially supported by the Fundação de Amparo à Pesquisa do Estado de São Paulo (FAPESP) - São Paulo Research Foundation (process 2018/19747-2).

\section{- Authors' contributions}

"RCM analyzed and interpreted data and was a major contributor in writing the manuscript. $\mathrm{MBH}$ performed the statistical analysis, was a contributor in writing the manuscript, and was the author who submitted the manuscript. EB analyzed and interpreted data and was an important contributor in writing the manuscript. All authors read and approved the final manuscript."

- Acknowledgements

Not applicable" in this section.

\section{References}

Adams SM (1990) Status and use of biological indicators for evaluating the effects of stress on fish. Am. Fish. Soc. Symposium 8:1-8

APHA (1995) Standard Methods for the Examination of Water and Wastewater. 19th Edition, American Public Health Association Inc., New York.

Baldwin DH, Spromberg JA, Collier TK, Scholz NL (2009) A fish of many scales: extrapolationg sublethal pesticide exposures to the productivity of wild salmon populations. Ecol Appl 198(8):204-215. https://doi.org/10.1890/08-1891.1

Barbieri E, Ngan PV, Gomes V (1998) Efeito do DSS, dodecil sulfato de sódio, no metabolismo e na capacidade de natação de Cyprinus carpio. Rev Bras Biol 58(2):263-271

Barbieri E, Paes ET (2011) The use of oxygen consumption and ammonium excretion to evaluate the toxicity of cadmium on Farfantepenaeus paulensis with respect to salinity. Chemosphere 84:9-16. https://doi.org/10.1016/j.chemosphere.2011.02.092 
Barbieri E (2007a) The use of active metabolism and swimming activity to evaluate the toxicity of Dodecyl Benzene Sodium Sulfonate (LAS-C12) on the Mugil platanus (Mullet) according to temperature and salinity. Water Environ Res 79:707-719. https://doi.org/10.2175/106143007X196697

Barbieri E (2007b) Use of metabolism and swimming activity to evaluate the sublethal toxicity of surfactant (LAS-C12) on Mugil platanus. Braz Arch Biol Technol 50:101-112.

https://doi.org/10.1590/S1516-89132007000100012

Barbieri E, Doi SA (2011) The effects of different temperature and salinity levels on the acute toxicity of zinc in the Pink Shrimp (Farfantepenaeus paulensis). Mar Freshwater Behav Physiol 44(4):251-263. https://doi.org/10.1080/10236244.2011.617606

Barbieri E, Moreira P, Luchini LA, Hidalgo KR, Muñoz A (2013) Assessment of acute toxicity of carbofuran in Macrobrachium olfersii (Wiegmann, 1836) at different temperature levels. Toxicol Ind Health 291-8. https://doi.org/10.1177/0748233713484655

Barbieri E, Ruíz-Hidalgo K, Rezende LAFG, Sabino FP (2017) Efectos del carbofuran en juveniles de Oreochromis niloticus en la toxicidad, metabólica de rutina y los parâmetros hematológicos. Bol Inst Pesca 43:513-526. https://doi.org/10.20950/1678-2305.2017v43n4p513

Barbieri E, Ferrarini AMT, Rezende KFO, Martinez DST, Alves OL (2018) Effects of multiwalled carbon nanotubes and carbofuran on metabolism in Astyanax ribeirae, a native species. Fish Physiol Biochem 44:1-10. https://doi.org/10.1007/s10695-018-0573-2

Barreto RE, Volpato GL (2006) Ventilatory frequency of Nile tilapia subjected to different stressors. J Exp Anim Sci 43:198-196

Britto RS, Garcia ML, Rocha AM, Flores JA, Pinheiro MVB, Monserrat JM, Ferreira JLR (2012) Effects of carbono nanomaterials fullerene $\mathrm{C} 60$ and fullerol $\mathrm{C} 60(\mathrm{OH}) 18-22$ on gills of fish Cyprinus carpio (Cyprinidae) exposed to ultraviolet radiation. Aquat Toxicol 114-115:80-87. https://doi.org/10.1016/j.aquatox.2012.02.018

Bosisio F, Rezende KFO, Barbieri E (2017) Alterations in the hematological parameters of Juvenile Nile Tilapia (Oreochromis niloticus) submitted to different salinities. Pan-Am J Aquat Sci 12:146-154

Campos-Garcia J, Martinez DST, Rezende KFO, Silva JRMC, Alves OL, Barbieri E (2016) Histopathological alterations in the gills of Nile tilapia exposed to carbofuran and multiwalled carbon nanotubes. Ecotoxicol Environ Saf 133:481-488. http://dx.doi.org/10.1016/j.ecoenv.2016.07.041

Carneiro JS, Barbieri E, Rezende KFO, Barros LC, Henriques MB (2020) Salinity effects in metabolic rate and behavior in lambari Astyanax bimaculatus. Braz J Anim Environ Res 3:2165-2179.

https://doi.org/10.34188/bjaerv3n3-127 
Christiansen PD, Brozek K, Hansen BW (1998) Energetic and behavioral responses by the common goby, Pomatoschistus microps (Kroyer), exposed to linear alkylbenzene sulfonate. Environ Toxicol Chem 17:2051-2057. https://doi.org/10.1002/etc.5620171022

De-Boeck G, De Smet H, Ronny B (1995) The effect of sublethal levels of copper on oxygen consumption and ammonia excretion in the common carp, Cyprinus carpio. Aquat Toxicol 32:127-141. https://doi.org/10.1016/0166-445X(94)00086-6

Diniz NM, Honorato CA (2012) Algumas alternativas para diminuir os efeitos do estresse em peixes de cultivo - Revisão. Arq Cienc Vet Zool 15:149-154

Dhamagaye HB, Gowda GC, Shruthisree C, Nayaka H, Meshran SJ (2015) Alteration in oxygen consumption and ammonia excretion of iridescent shark, Pangasinodon hypophthalmus exposed to cypermethrin. J Exp Zool 18:381-385

Fonseca T, Costa-Pierce BA, Valenti WC (2017) Lambari Aquaculture as a Means for the Sustainable Development of Rural Communities in Brazil. Rev Fish Sci Aquac 25:316-330 https://doi.org/10.1080/23308249.2017.1320647.

Henriques MB, Fagundes L, Petesse ML, Silva NJR, Rezende KFO, Barbieri E (2018) Lambari fish Deuterodon iguape Eigenmann, 1907 as an alternative to live bait for estuarine recreational fishing. Fish Manag Ecol 25:400-407. https://doi.org/10.1111/fme.12308

Henriques MB, Carneiro JS, Fagundes L, Castilho-Barros L, Barbieri E (2019) Economic feasibility for the production of live baits of lambari (Deuterodon iguape) in recirculation system. Bol Inst Pesca 45(4): e516. https://doi.org/10.20950/1678-2305.2019.45.4.516

Herbrandson C, Bradbury SP, Swackhamer DL (2003) Influence of suspended solids on acute toxicity of carbofuran to Daphnia magna. I. Interactive effects. Aquat Toxicol 63:333-342. https://doi.org/10.1016/s0166-445x(02)00206-0

Hernández-Moreno D, Pérez-López M, Soler F, Gravato C, Guilhermino L (2011) Effects of carbofuran on the sea bass (Dicentrarchus labrax L.): study of biomarkers and behavior alterations. Ecotoxicol Environ Saf 74:1905-1912. https://doi.org/10.1016/j.ecoenv.2011.07.016

Iwama GK, Afonso L, Todgham A, Ackerman P, Nakano K (2004) Are hsps suitable for indicating stressed states in fish? J Exp Biol 204:15-19. https://doi.org/10.1242/jeb.00707

Jash NB, Bhattacharaya S (1983) Delayed toxicity of carbofuran in fresh water teleost Channa punctatus. Indian J Exp Biol 17:693-697

Klaper R, Arndt D, Chen J, Goetz F (2010) Functionalization impacts the effects of carbon nanotubes on the immune system of Rainbow trout, Oncorhynchus mykiss. Aquat Toxicol 100:211-217. https://doi.org/10.1016/j.aquatox.2010.07.023

Page $12 / 19$ 
Lal B (2007) Pesticide - induced reproductive dysfunction in Indian fishes. Fish Physiol Biochem 33:455462. https://doi.org/10.1007/s10695-007-9171-4

Lemaire P, Sturve J, Forlin L, Livingstone DR (1996) Studies on aromatic hydrocarbon quinone metabolism and DT-Diaphorase function in liver of fish species. Mar Environ Res 2:317-321. https://doi.org/10.1016/0141-1136(95)00042-9

Little EE, Archeski RD, Flerox BA, Kozlovskaya VI (1990) Behavioral indicators of sublethal toxicity in rainbow trout. Arch Environ Contam Toxicol 19:380-385. https://doi.org/10.1007/BF01054982

Little EE, Finger SE (1990) Swimming behavior as an indicator of sublethal toxicity in fish. Environm Toxic Chem 9:13-19

Lombardi JV (2004) Fundamentos de toxicologia aquática. In: Ranzani-Paiva MJT, Takemoto RM, Lizama MAP (ed) Sanidade de organismos aquáticos. 1st edn. Varela, São Paulo, pp 263-272

MacLead JC, Smith Jr LL (1966) Effects of pulpwood fiber on oxygen consumption. Ph.D. Thesis, University of London. 126p.

MarquesMN, CotrimMB, PiresMAF, Filho OB (2007) Avaliação do impacto da agricultura em áreas de proteção ambiental, pertencentes à bacia hidrográfica do Rio Ribeira de Iguape, São Paulo. Quim Nova $30: 1171-1178$

Maxuwell LB, Dutta HM (2005) Diazinon-induced endocrine disruption in bluegill sunWsh, Lepomis macrochirus. Ecotoxicol Environ Saf 60:21-27. https://doi.org/10.1016/j.ecoenv.2003.12.015

Pereira VM, Bortolotto JW, Kist LW, Azevedo MB, Fritsch RS, Oliveira RL, Pereira TC, Bonan CD, Vianna MRM, Bogo MR (2012) Endosulfan exposure inhibits brain AChE activity and impairs swimming performance in adult zebrafish (Danio rerio). Neurotoxicology 33:469-475

https://doi.org/10.1016/j.neuro.2012.03.005

Rand GM (1984) The use of behavioral measurements to assess toxicant induced stress in marine organisms. In: Persoone G, Jaspers E, Claus C (ed) Ecotoxicological testing for the marine environment, vol.2. Institute for Marine Scientific Research, Bredene, Belgium, pp.431-456

Rand GM, Petrocelli SR (1985) Fundamentals of aquatic toxicology: Methods and applications. United States, pp 335-373

Rebelo RM, Caldas ED (2014) Avaliação de risco ambiental de ambientes aquáticos afetados pelo uso de agrotóxicos. Quim Nova 37:1199-1208. https://doi.org/10.5935/0100-4042.20140165.

Reidy SP, Nelson JÁ, Tang Y, Kerr SR (1995) Post-exercise metabolic rate in Atlantic cod and its dependence upon the method of exhaustion. J Fish Biol 47:377-386. https://doi.org/10.1111/j.10958649.1995.tb01907.x 
Reigala CS, Luchimi LC, Barbieri E (2014) Presença de organoclorados em amostras de água e ostras Crassostrea sp. do município de Cananeia-SP. Mundo Saúde 38:66-74. DOI:

https://doi.org/10.15343/0104-7809.20143801066074

Ruíz-Hidalgo K, Masís-Mora M, Barbieri E, Carazo-Rojas E, Rodriguez-Rodriguez CE (2016) Ecotoxicological analysis during the removal of carbofuran in fungal bioaugmented matrices. Chemosphere 144:864-871. https://doi.org/10.1016/j.chemosphere.2015.09.056

Sabra FS, Mehana EE (2015) Pesticides toxicity in fish with particular reference to inseticides. Asian J Agric Food Sci 3: 12p. https://doi.org/10.24203/AJAFS.V3I1.2156

Santana LM, Cavalcante RM (2016) Transformações metabólicas de agrotóxicos em peixes: uma revisão. Orbital: Electron J Chem 8:257-268. http://dx.doi.org/10.17807/orbital.v8i4.856

Silva ALF, Chagas EC, Gomes LC, Araujo LD, Silva CR, Brandão FR (2006) Toxicity and sublethal effects of potassium permanganate in Tambaqui (Colossoma macropomum). J World Aquacult Soc 37:318-321

Valencia EC, Guerrero JD, de Yunda LA, Martínez MC (2008) Evaluación de la adsorción-desorción de 14C-carbofuran y Furadan 3SC $\circledast$ en tres suelos de Cundinamarca (Colombia). Rev Colomb Quim 37:7991

Van der Oost R, Beyer J, Vermeulen NPE (2003) Fish bioaccumulation and biomarkers in environmental risk assessment: a review. Environ Toxicol Pharmacol 13:149-157 http://dx.doi.org/10.1016/S13826689(02)00126-6.

Vargas M, Correa M, Chung KS (1991) Indicadores fisiologicos en la evaluacion de la toxicidad de hidrocarburos aromaticos. Bol Inst Oceanog Venez Univ Oriente: 30:57-64

Winkler L (1888) Methods for measurement of dissolved oxygen. Ber Deutsch Chem Ges 21:2843-2854

Zagatto PA, Bertoletti E (2006) Ecotoxicologia aquática: princípios e aplicações. Editora Rima, São Carlos, São Paulo, $472 p$

\section{Figures}




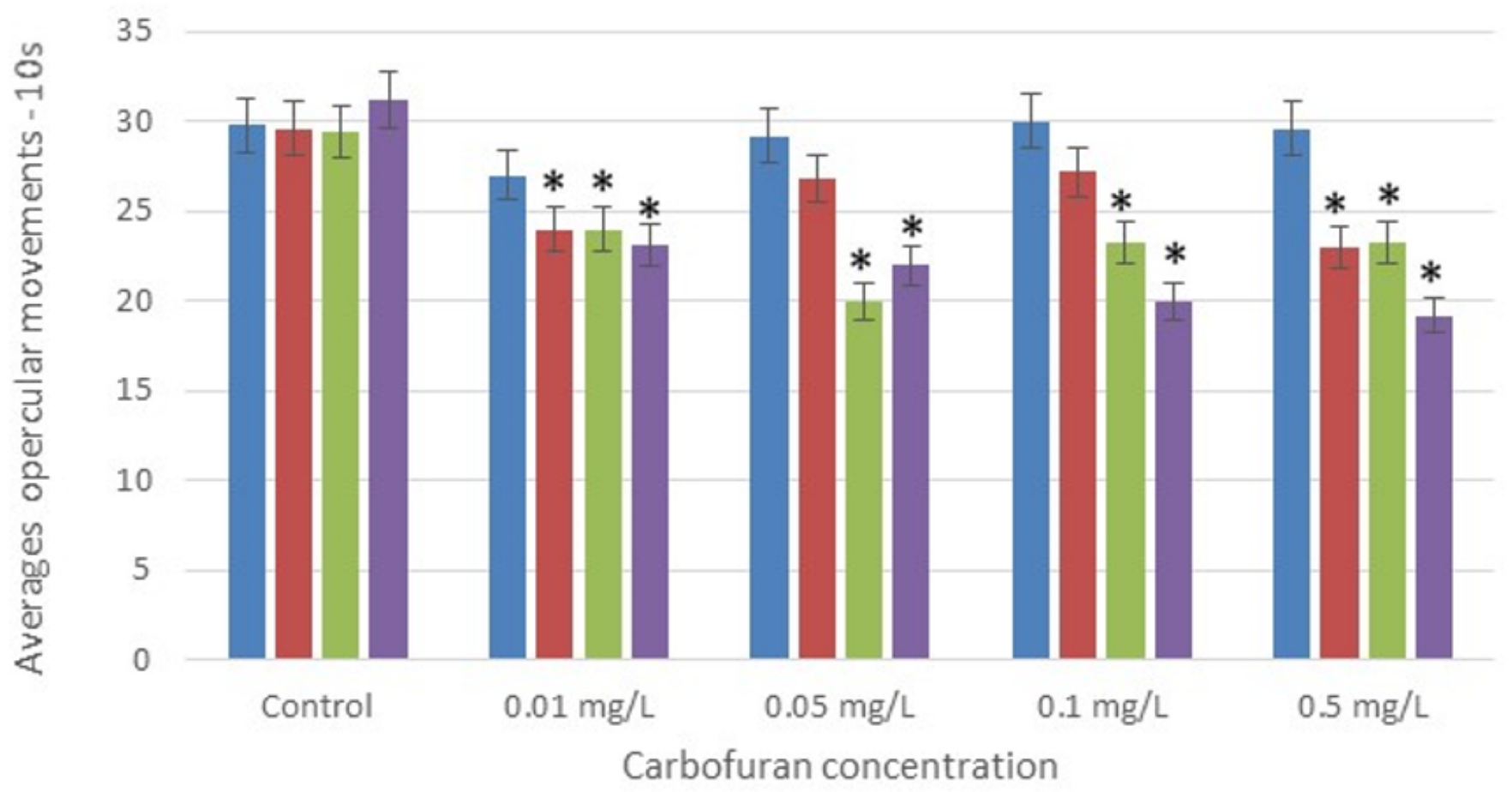

$\square 0 \mathrm{~h}=2 \mathrm{~h}=24 \mathrm{~h}=48 \mathrm{~h}$

\section{Figure 1}

Averages of opercular movements $(n=5)$, of each group, for fish exposed to different concentrations of carbofuran, in the exposure periods of $0,2,24$ and 48 hours. The bars are the respective standard deviations and the asterisks represent the concentrations where there was a statistical difference in relation to the control 


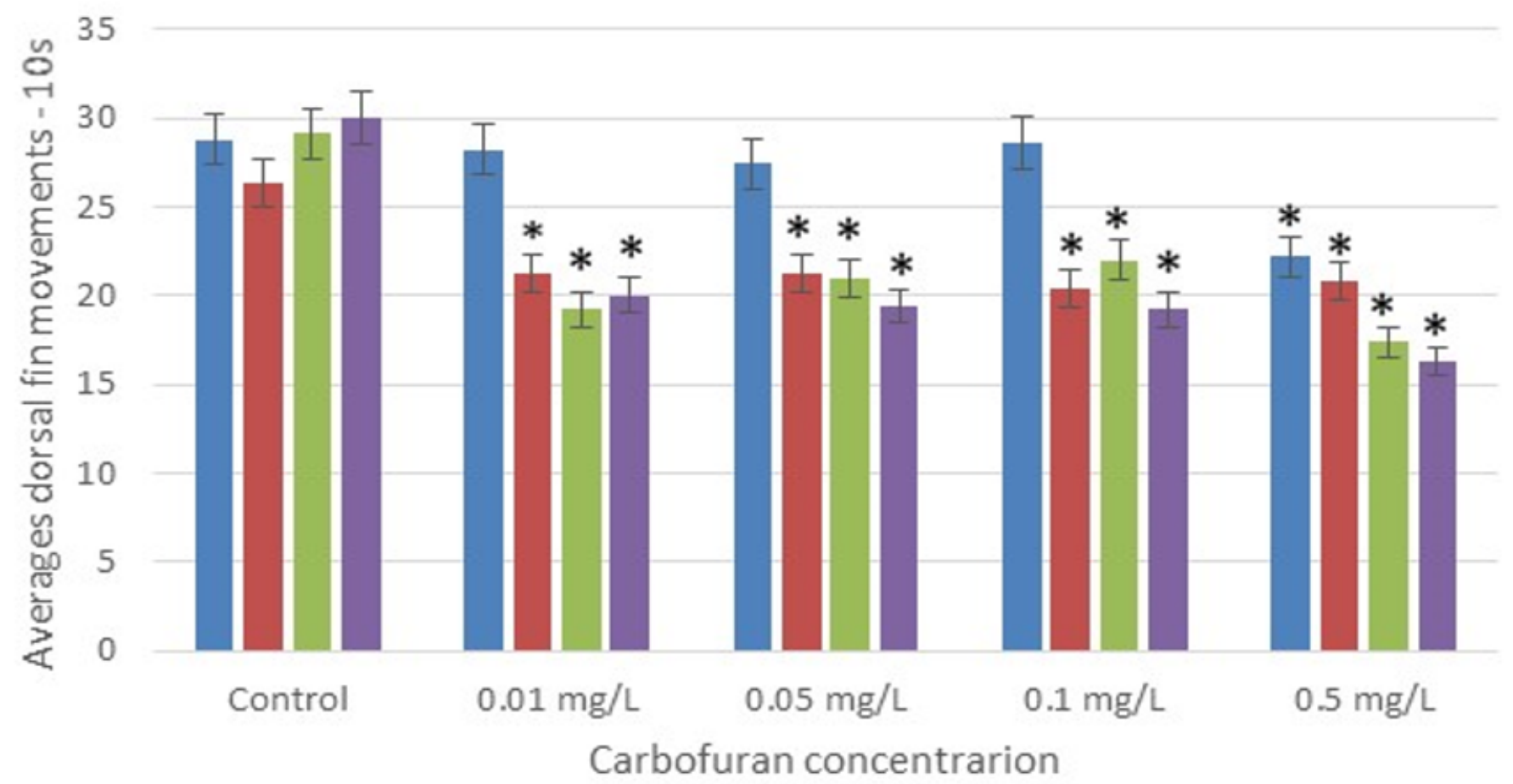

Figure 2

Average dorsal fin movements $(n=5)$ for fish exposed to different concentrations of carbofuran, in the exposure periods of $0,2,24$, and 48 hours. The bars are the respective standard deviations and the asterisks represent the concentrations where there was a statistical difference in relation to the control 


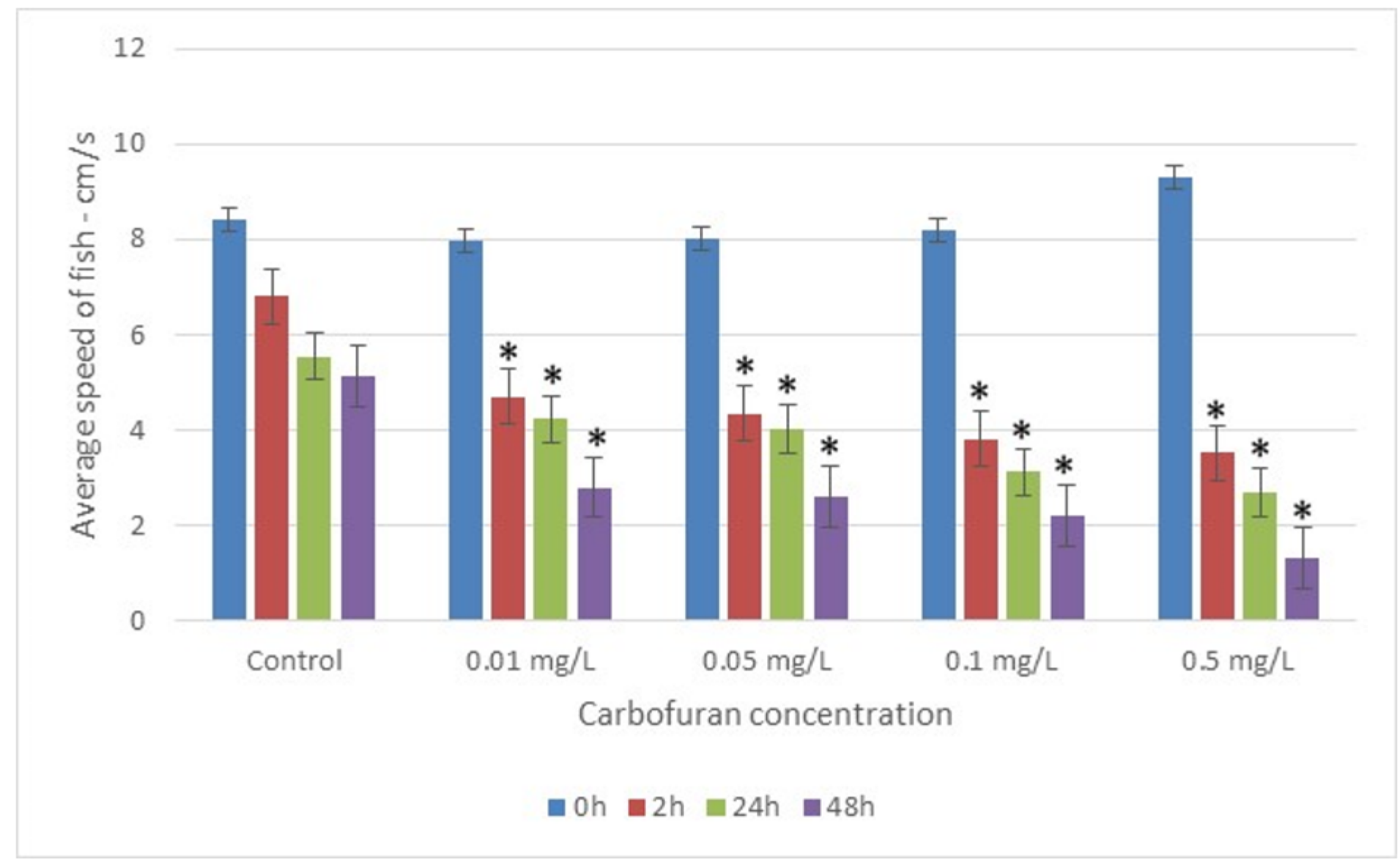

\section{Figure 3}

Swimming speed averages $(n=5)$ for fish exposed to various concentrations of carbofuran at various periods of exposure. The bars are the respective standard deviations and the asterisks represent the concentrations where there was a statistical difference in relation to the control 


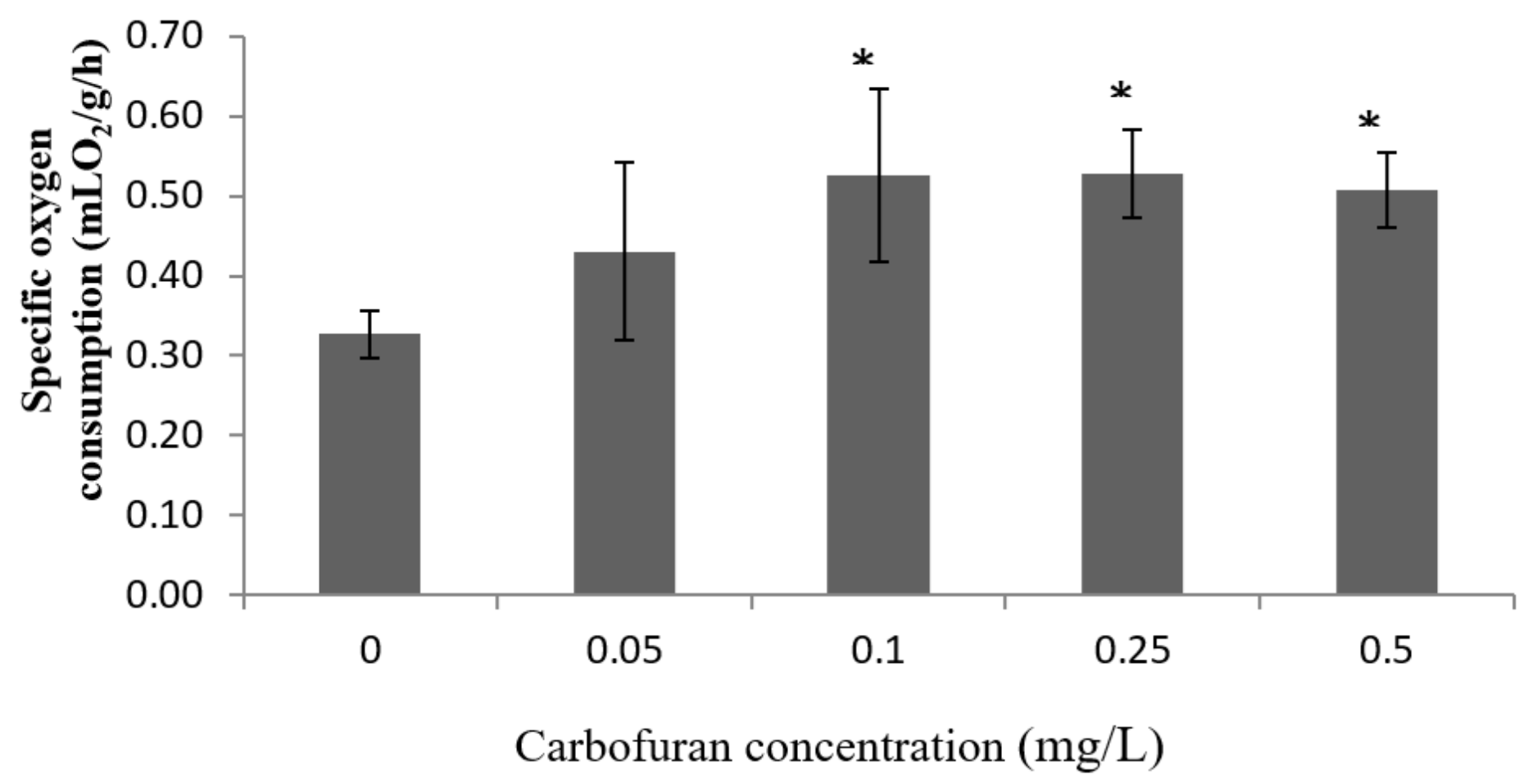

Figure 4

Specific oxygen consumption averages of $\mathrm{D}$. iguape in relation to carbofuran concentration. The bars are the respective standard deviations and the asterisks are the statistical differences in relation to the control $(n=5)$

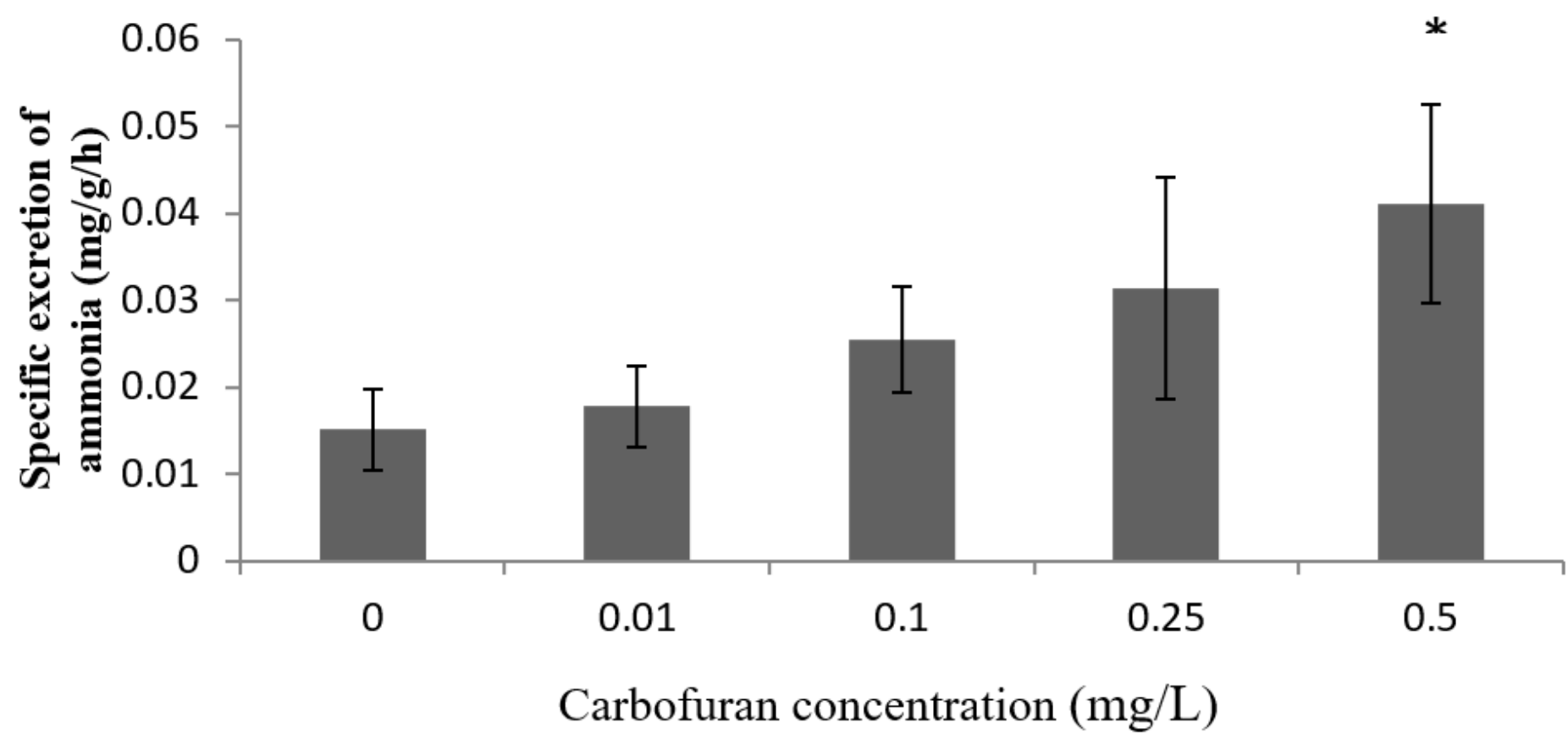

Figure 5 
Specific ammonia excretion averages of D. iguape in relation to the concentration of carbofuran, the bars are the respective standard deviations and the asterisk is the statistical difference in relation to the control $(n=5)$ 